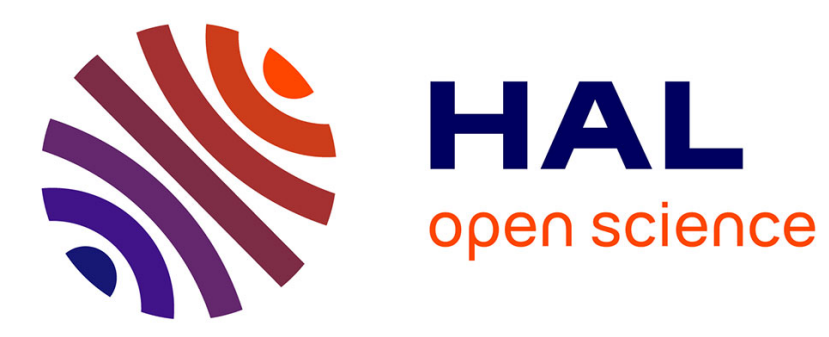

\title{
Revealing Carbon Phenomena at Palladium Nanoparticles by Analyzing the Work Function Henrik Grönbeck, Clemens Barth
}

\section{To cite this version:}

Henrik Grönbeck, Clemens Barth. Revealing Carbon Phenomena at Palladium Nanoparticles by Analyzing the Work Function. Journal of Physical Chemistry C, 2019, 123 (7), pp.4360-4370. 10.1021/acs.jpcc.8b12208 . hal-02060929

\section{HAL Id: hal-02060929 \\ https://hal.science/hal-02060929}

Submitted on 12 Feb 2022

HAL is a multi-disciplinary open access archive for the deposit and dissemination of scientific research documents, whether they are published or not. The documents may come from teaching and research institutions in France or abroad, or from public or private research centers.
L'archive ouverte pluridisciplinaire HAL, est destinée au dépôt et à la diffusion de documents scientifiques de niveau recherche, publiés ou non, émanant des établissements d'enseignement et de recherche français ou étrangers, des laboratoires publics ou privés. 


\title{
Revealing Carbon Phenomena at Palladium
}

\section{Nanoparticles}

\section{by Analyzing the Work Function}

\author{
Henrik Grönbeck ${ }^{\dagger}$ and Clemens Barth ${ }^{*, \dagger}$
}

Chalmers University of Technology, Department of Physics and Competence Centre for

Catalysis, SE-41296 Göteborg, Sweden, and Aix-Marseille Université, CNRS, CINaM UMR

7325, 13288 Marseille, France

E-mail: barth@cinam.univ-mrs.fr

${ }^{*}$ To whom correspondence should be addressed

${ }^{\dagger}$ Chalmers University of Technology, Department of Physics and Competence Centre for Catalysis, SE41296 Göteborg, Sweden

${ }^{\ddagger}$ Aix-Marseille Université, CNRS, CINaM UMR 7325, 13288 Marseille, France 


\begin{abstract}
Carbon at metal nanoparticles (NPs) plays a fundamental role in heterogeneous catalysis. However, as experimental detection of small amounts of carbon is difficult, in particular when occupying subsurface sites, reaction mechanisms involving absorbed carbon are highly debated. Here we show that the work function (WF) of metal NPs can be used as a measure of carbon adsorption and absorption, which we demonstrate by Kelvin probe force microscopy (KPFM) and density functional theory (DFT) calculations for (111) faceted palladium NPs (PdNPs) on graphite. A growth of PdNPs between 150 and $480^{\circ} \mathrm{C}$ leads to carbon etching of the graphite steps and carbon $a b$ sorption into the first subsurface layer of the NP's facets. This strongly reduces the WF of $\operatorname{Pd}(111)$ by up to $-1 \mathrm{eV}$. During a 1 hour long post-annealing at $650{ }^{\circ} \mathrm{C}$, more carbon is etched from the graphite steps, leading to a carbon precursor structure adsorbed on the NP's facets, as verified by scanning tunnellig microscopy. The carbonaceous structures are replaced by graphene upon further annealing (1 to 2 hours), followed by a decrease in the WF by $\sim-1.4 \mathrm{eV}$. Similar phenomena are observed after short-time ethylene decomposition at PdNPs at $650^{\circ} \mathrm{C}$. Apart from subsurface carbon, we suggest that the large WF shifts observed experimentally are related to structural defects on the NP's facets.
\end{abstract}




\section{INTRODUCTION}

Carbon at metal nanoparticles (NPs) plays a major role in heterogeneous catalysis, in particular with respect to catalyst de-activation ${ }^{1,2}$, hydrogenation reactions ${ }^{3,4}$, Fischer-Tropsch synthesis ${ }^{5}$ and in view of the formation of various carbon structures such as nanotubes ${ }^{6,7}$, shells ${ }^{8}$ and graphene ${ }^{9,10}$. Apart from different carbon structures, elemental carbon can at low cencentrations also be adsorbed on ${ }^{11}$ or absorbed below the NP's facets ${ }^{12,13}$, in some cases, forming a metal carbide ${ }^{14,15}$. Large structures can be directly characterized by transmission electron microscopy (TEM) ${ }^{6-10}$ whereas graphene ${ }^{16,17}$ and small amounts of carbon adsorbed on the NP's facets are best analyzed by $\mathrm{STM}^{17}$. X-ray diffraction (XRD) is commonly used to analyze carbon in carbide $\mathrm{NPs}^{15,18,19}$, with TEM allowing a quantification of carbon at a single $\mathrm{NP}^{14,15}$.

In comparison to adsorbed carbon or the carbide, it is more challenging to detect and characterize small amounts of subsurface carbon in metals, which have a non-neglectable carbon solubility like palladium, iron, nickel and $\operatorname{cobalt}^{20}$ : the identification of subsurface carbon by STM generally remains speculative ${ }^{21}$, and in only a few cases carbon might be suspected to be subsurface ${ }^{22,23}$. In general, subsurface carbon has been infered by analyzing chemical reactions that change when subsurface carbon is present, as exemplified by hydrogenation reactions at palladium NPs $(\operatorname{PdNPs})^{13,24}$. However, in many cases the support by density functional theory (DFT) calculations is needed for the interpretation ${ }^{13,25}$ : in the case of palladium, which commonly is used to catalyze hydrogenation and oxidation reactions ${ }^{26}$, several carbon configurations have been considered: subsurface carbon below $\operatorname{Pd}(111)$ surfaces ${ }^{11,27-29}$ and below the facets of $\operatorname{PdNPs}^{12,13,30}$ and, for slightly higher carbon contents (0.5 to 1 monolayer), C-Pd-C bridging-metal structures ${ }^{31}$ and carbon oligomers ${ }^{11,31}$ on the surface $^{11,28,29,31}$. The suggestions concerning carbon structures put forth in these computational studies call for experiments, which can detect, in particular, subsurface carbon. Most computational work rely on pristine $\operatorname{Pd}(111)$ surfaces without taking into account possible reconstructions of the metal surface when carbon is located on and/or below the surface. 
Intuitively, this might be a simplification as reactions often take place at high temperatures where the surface can be subjected to carbon-initiated surface reconstructions as recently discussed $^{32}$.

A possible experimental method to detect carbon on or in a metal is to analyze the surface work function (WF). It is well known that carbon sensitively reduces the WF of, e.g., palladium surfaces ${ }^{33,34}$. In addition, low-energy electron microscopy (LEEM) have been used to study carbon segregation phenomena on $\mathrm{Pd}(111)$ by analyzing WF changes that are typically in the range of several hundreds of millivolts ${ }^{35}$. However, to study carbon phenomena at the single NP level, scanning probe microscopy (SPM) is needed. A suitable SPM technique is Kelvin probe force microscopy $(\mathrm{KPFM})^{36}$, which is an implementation of the classical Kelvin method into noncontact atomic force microscopy (nc-AFM) ${ }^{36}$ with a nanometer and $\mathrm{mV}$ resolution in space and $\mathrm{WF}$, respectively. Reliable $\mathrm{WF}$ values for $\mathrm{NPs}^{37}$ and also graphene ${ }^{38}$ on $\mathrm{SiC}^{39}$ and insulator surfaces ${ }^{40}$ can be obtained.

In the present combined SPM and DFT study, we have explored the WF change of palladium NPs (PdNP) upon carbon adsorption and absorption. The NP are grown in their (111) epitaxy on highly oriented pyrolytic graphite surfaces (HOPG) in ultra-high vacuum (UHV). HOPG is commonly used as a support and carbon source ${ }^{16}$ and has the advantage of being inert towards gas molecules ${ }^{41}$, so that chemical reactions can be unambiguously assigned to the supported PdNPs only. We show that a growth of PdNPs at already moderate temperatures $\left(150\right.$ to $480^{\circ} \mathrm{C}$ ) leads to absorption of carbon from HOPG steps into the NPs. Carbon adsorption on PdNPs is observed upon extended post-annealing experiments at $650^{\circ} \mathrm{C}$, where carbon precursor structures and graphene eventually are formed. Similar phenomena appear when cracking ethylene at same temperatures. Our work indicates that the palladium NP facets undergo reconstructions during the growth of the carbon structures - a viewpoint that has not been stressed before for PdNPs. 


\section{METHODS}

Experimental Details. Clean surfaces are prepared by cleaving HOPG either in UHV ( $U H V$ cleaved $H O P G$ ) or in air. When cleaved in air, the sample is additionally annealed at $\sim 650{ }^{\circ} \mathrm{C}$ in UHV during several hours ( $U H V$ annealed $H O P G$ ). The PdNPs are grown by evaporating neutral palladium atoms onto the HOPG sample. During the growth, the HOPG substrate is held at a constant temperature between room temperature $(\mathrm{RT})$ and $480{ }^{\circ} \mathrm{C}$. For experiments with ethylene, the UHV chamber is back-filled with ethylene via a leakage valve at a pressure of $1.0 \times 10^{-6}$ mbar and the dosage is determined by the exposure time. During the ethylene exposure, the sample is held at a constant temperature of $\sim 650{ }^{\circ} \mathrm{C}$.

STM, STS, nc-AFM and KPFM experiments are performed in the same ultra-high vacuum $(\mathrm{UHV})$ chamber $\left(6 \times 10^{-11} \text { mbar base pressure }\right)^{42}$ with a room temperature AFM/STM. KPFM is used in the frequency modulation mode ${ }^{43}$ and applied during the nc-AFM topography imaging mode. During the scanning of the surface, the electrostatic tip-surface interaction is minimized at each image point by the bias voltage, yielding the contact potential difference $(\mathrm{CPD})$ between tip and surface defined as $\mathrm{CPD}=\left(\phi_{\text {sample }}-\phi_{\text {tip }}\right) / e$. The so-called work function image is obtained simultaneously with the topography nc-AFM image. Because of $\triangle \mathrm{CPD}=\mathrm{CPD}_{1}-\mathrm{CPD}_{2}=\left(\phi_{1}-\phi_{2}\right) / e=\triangle \phi / e$ at two surface sites (1 and 2), the contrast of a WF image is directly related to WF differences on the surface. A bright and, in particular, orange/yellow contrast in WF images corresponds to a high WF, whereas a violet and black contrast corresponds to a low WF. For simplicity, the WF of the HOPG terraces is calibrated to be zero such that variations in the profiles directly correspond to the WF difference $\triangle \phi_{\text {NP-HOPG }}$ between palladium islands/NPs and HOPG.

DFT Calculations. DFT is used as implemented in the $\mathrm{Dmol}^{3}$ program $^{44}$. The calculations are performed either within the local density approximation (LDA) ${ }^{45}$ or within the generalized gradient approximation (GGA) using the functional proposed by Perdew, Burke, and Ernzerhof $(\mathrm{PBE})^{46}$. LDA is considered as this functional, due to error cancellations, is known to provide good results for surface properties such as surface energies and work- 
functions $^{47,48}$. The $\operatorname{Pd}(111)$ surface is modeled with 7 layers using two different surface cells; $\sqrt{3} \times \sqrt{3}$ and $p(2 \times 2)$. Geometry optimization is performed using the BFGS method. The work function $(\phi)$ is the energy needed to remove an electron from the bulk of palladium to the vacuum. It is calculated according to: $\phi=V_{\text {vacuum }}-\epsilon_{F}$, where $V_{\text {vacuum }}$ is the electrostatic potential in the vacuum region and $\epsilon_{F}$ is the Fermi energy.

More details about the materials, work function values and sample preparation as well as details about STM, nc-AFM, KPFM and DFT can be found in the Supporting Information.

\section{RESULTS}

WF Reduction During the NP Growth. After a growth of 3 monolayer (ML) palladium on HOPG at room temperature (RT), palladium islands are formed, which are anchored at the steps of the HOPG surface. Figure 1a shows a typical island, which has a height of $2.1 \mathrm{~nm}$ and a surface area that corresponds to the area of a disk with a radius of $130 \mathrm{~nm}$. The edges of the islands form angles of $120^{\circ}$ or $60^{\circ}$, which is due to the (111) orientation of the top facets of the islands. The WF image in Figure 1a shows a violet contrast on the HOPG surface, which corresponds to small WF values, and a bright yellow contrast above the $\mathrm{Pd}$ islands corresponding to high $\mathrm{WF}$ values. The profile underneath the WF image exhibits the variations of the WF. The WF difference between the palladium islands and HOPG is positive $(\triangle \phi=+1.4 \mathrm{eV})$, which means that the WF of the palladium island is higher than the WF of HOPG. Thus, with our calibrated WF value of $\phi_{\mathrm{HOPG}}=4.3 \pm 0.1 \mathrm{eV}$ for HOPG (see Supporting Information), the Pd islands are measured to have a WF of $\phi_{\mathrm{HOPG}}+\triangle \phi=5.7 \pm 0.1 \mathrm{eV}$. This value is in good agreement with the experimental literature value of $\phi_{\mathrm{Pd}, \text { lit }}=5.6 \pm 0.1 \mathrm{eV}$ for bulk $\mathrm{Pd}(111)$ (see Supporting Information) and with our theoretical value of $\phi_{\mathrm{Pd}, \mathrm{LDA}}=5.7 \mathrm{eV}$ obtained by DFT-LDA. This result confirms that the islands are composed of clean palladium. Note that we can indeed compare the WF of the Pd islands and all following NPs with the $\operatorname{Pd}(111)$ single crystal surface because these 

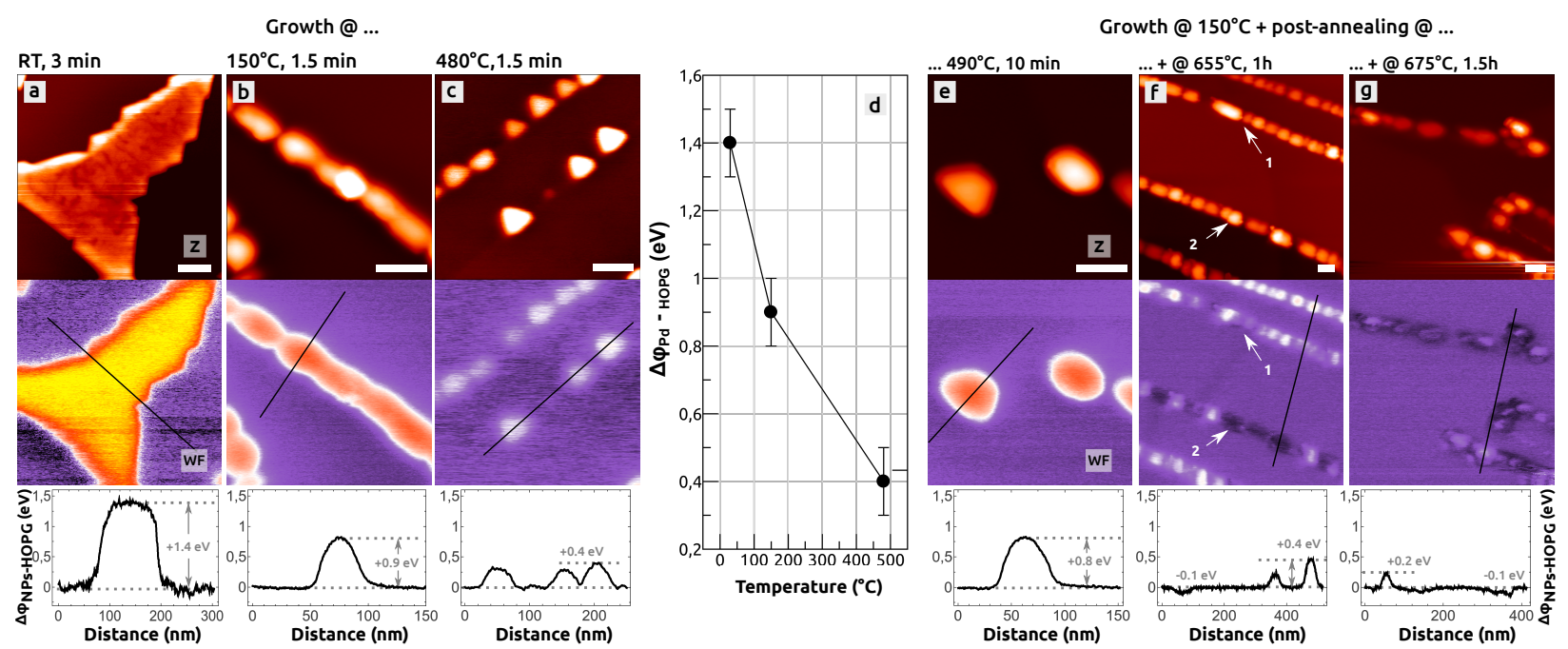

Figure 1: The WF dependence of HOPG supported PdNPs on the growth temperature and post-annealing. One KPFM experiment is represented by a pair of two vertically arranged images with a representative WF profile underneath. The images on the top represent the topography (z) and the images below the WF. (a-c) Pd islands (a) and PdNPs (b,c) on UHV cleaved (a) and UHV annealed HOPG (b,c) after a growth at $28^{\circ} \mathrm{C}(\mathrm{a}), 150{ }^{\circ} \mathrm{C}(\mathrm{b})$ and $483^{\circ} \mathrm{C}$ (c). (d) The temperature dependent WF difference $\triangle \phi_{\text {NPs-HOPG }}=\phi_{\mathrm{Pd}}-\phi_{\mathrm{HOPG}}$ with values extracted form the WF images in (a-c). (e-g) Same PdNP/HOPG sample from (b) after three successive post-annealing treatments: $10 \mathrm{~min}$ at $490^{\circ} \mathrm{C}(\mathrm{e}), 1.0 \mathrm{~h}$ at $665^{\circ} \mathrm{C}(\mathrm{f})$ and $1.5 \mathrm{~h}$ at $675^{\circ} \mathrm{C}(\mathrm{g})$. Nominal Pd thickness: $3 \mathrm{ML}$ (a) and $1.5 \mathrm{ML}$ (b,c,e-g). NP dimension (mean values): $h_{\mathrm{NP}}=2$ (a), 8 (b), 7 (c), 12 (e), 6 (f) and $7 \mathrm{~nm}(\mathrm{~g}), r_{\mathrm{NP}}=131$ (a), 17 (b), 15 (c), 26 (e), 17 (f) and $20 \mathrm{~nm}$ (g). KPFM parameters: $\triangle f=-8.2$ (a), -19.9 (b), -6.7 (c), -19.1 (e), -16.5 (f) and $-14.4 \mathrm{~Hz}(\mathrm{~g}), U_{\mathrm{ac}}=350(\mathrm{~b}, \mathrm{e}-\mathrm{g}), 450$ (a) and $650 \mathrm{mV}$ (c), all: $v=0.5 \mathrm{~Hz}$ and $f_{\text {ac }}=650 \mathrm{~Hz}$, scale bars: $50 \mathrm{~nm}$ (all).

nano-objects still have a size large enough to assume bulk electronic properties ${ }^{49}$.

Figure $1 \mathrm{~b}$ and $\mathrm{c}$ show two other HOPG samples, which have been kept at $150{ }^{\circ} \mathrm{C}$ and $480^{\circ} \mathrm{C}$, respectively, during the evaporation of palladium. Note that a HOPG sample is quickly put into the hot oven, which is kept at the growth temperature. The sample then remains inside the oven for about 1.5 min during the NP growth. After the growth, the sample is immediately extracted from the UHV oven to reduce possible surface reactions of the NPs that may take place at the high temperature.

At a growth temperature of $150{ }^{\circ} \mathrm{C}$ and $480^{\circ} \mathrm{C}$, NPs instead of islands are formed at the steps of the HOPG surface, which is due to an increased mobility of palladium at these temperatures. The NPs can have a height between $h_{\mathrm{NP}}=4$ and $13 \mathrm{~nm}$ and a surface area 
that corresponds to a disk with a radius between $r_{\mathrm{NP}}=10$ and $20 \mathrm{~nm}$. The WF images and respective profiles clearly show that with increasing growth temperature, the WF difference between such as-prepared PdNPs and HOPG decreases by $-0.5 \mathrm{eV}$ with respect to the WF difference measured at the palladium islands (Figure 1a). This is a general trend also observed at many other NPs found on both samples. Because the palladium islands and NPs are grown under UHV conditions, the WF of the HOPG surface is always the same for all three samples. This means that the WF of the PdNPs is smaller (Figure $1 \mathrm{~b}$ and $\mathrm{c}$ ) than the WF of the islands made from clean palladium (Figure 1a). Figure 1d shows the trend of the WF reduction observed at the NPs: from room temperature to $480{ }^{\circ} \mathrm{C}$ the WF of palladium decreases by $-1.0 \mathrm{eV}$. Another important observation is, that when imaging the as-prepared NPs by STM, the NPs are in many cases displaced laterally by the STM tip and only high bias voltages and small tunnel currents can be used for the imaging (Figure S2 in the Supporting Information). Furthermore, the facets of the NPs measured by STM appear to be atomically flat.

At this point we conclude that the experiments show a WF reduction which is indicative that carbon is etched from the HOPG steps and absorbed inside the PdNPs (see section Discussion).

WF Reduction After Post-Annealing. It is interesting to study if a WF reduction is observed when the NPs are post-annealed at a temperature higher than the growth temperature. In Figure 1e to g, three KPFM experiments of the NPs grown at $150{ }^{\circ} \mathrm{C}$ (Figure 1b) are shown, after three successive post-annealing steps. In the first post-annealing step (Figure 1e), the PdNPs are annealed at a temperature of $480^{\circ} \mathrm{C}$, with an annealing time of 10 minutes. In this case, the initial WF of the PdNPs (Figure 1b) does not change. This means that a NP growth at $480{ }^{\circ} \mathrm{C}$ (compare with Figure 1c) leads to carbon inclusion into NPs whereas as-prepared NPs are inert towards an additional carbon absorption when they are post-annealed at the same temperature.

However, the WF of as-prepared NPs decreases dramatically during long post-annealings 
of hours at around $650{ }^{\circ} \mathrm{C}$ : in the second and third post-annealing step (Figure 1f and g), the WF of the NPs is much lower than before: after the second post-annealing during 1 hour, the WF difference between the PdNPs and HOPG measures $\triangle \phi=+0.4 \mathrm{eV}$, which can be seen at the NPs that are attached at mono-atomic high HOPG steps in the upper region of the topography image in Figure 1f (see arrow at position 1). In contrast, other NPs that are preferentially attached at the $2.5 \mathrm{~nm}$ high HOPG step (see arrow at position 2), show a dark contrast corresponding to a negative WF difference of $\sim-0.1 \mathrm{eV}$, i. e., the WF of those NPs $(\phi \approx 4.2 \mathrm{eV})$ is smaller than the one of HOPG $\left(\phi_{\mathrm{HOPG}}=4.3 \pm 0.1 \mathrm{eV}\right)$. After additional 1.5 hours during the third post-annealing step (Figure 1g), maximum and minimum values in the range of +0.2 and $-0.1 \mathrm{eV}$ are found, respectively.

The question arises, if the NP's facets show any adsorbed structures that can be correlated with the WF reduction. As already mentioned, the facets of as-grown PdNPs are atomically flat, i. e., they do not exhibit any adsorbed structures, and the NPs show a high mobility during STM imaging. However, a stable STM imaging with even low bias voltages and high tunnel currents is possible after the latter post-annealing steps at $\sim 650{ }^{\circ} \mathrm{C}$ (Figure $1 \mathrm{f}$ and g): the topography images in Figure 2a to c show clear features on the top (111) facet of a selected NP from the sample shown in Figure 1f. A truncated triangular shape of the NP can be seen (Figure 2a), which is typical for such NPs. The top facet does not appear atomically flat, instead it shows a rather disordered structure, which can be better seen in Figure 2b. The structure is partially composed of bright filaments with a length of a few nanometers and some atom-sized bright dots. In the atomically resolved image (Figure 2c), some atomic structures can be seen, which are composed of atoms keeping a distance of $1.5 \pm 0.2 \AA$. This filament structure is a carbon structure recently described in Ref. 17, involves carbon on facets ${ }^{11,28,31}$ and appears just before the growth of graphene ${ }^{17}$, thus, it is a precursor to graphene. The structure can be expected to appear also on all the other side facets stabilizing the NPs on the HOPG surface such that high-resolution STM is possible ${ }^{17}$.

At the edges of the NP in Figure 2a, small regions with a graphene moiré pattern are 

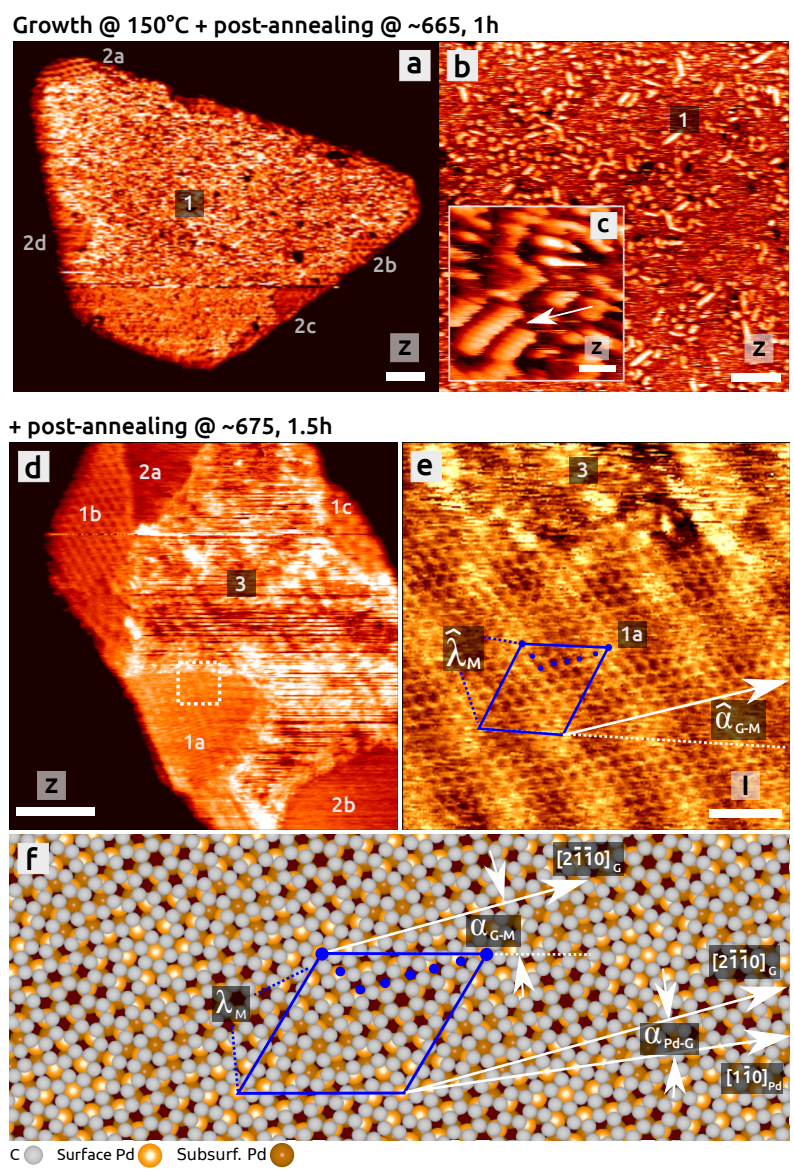

Figure 2: The carbon precursor structure (a-c) and graphene (d-f) on PdNPs after the two post-annealing steps at $\sim 660^{\circ} \mathrm{C}$ shown in Figure 1f and g, respectively. Post-annealing of the PdNPs leads first to the filament precursor structure (a-c), which gets then replaced by graphene upon longer annealing times (d,e). (f) Model of the $\lambda_{\mathrm{M}}=1.53 \mathrm{~nm}$ large $(\sqrt{31} \times \sqrt{31})-\mathrm{R} 8.9^{\circ}$ moiré pattern in image $(\mathrm{e})$, which was not observed before (see Table S1 for geometric properties). Images (a-d) show the topography signal whereas image (e) shows the tunnel current. STM parameters: $U_{\text {Bias }}=0.10$ (a,c), $0.064(\mathrm{~b}), 0.081(\mathrm{~d})$ and $0.051 \mathrm{~V}(\mathrm{e})$, $I=0.52(\mathrm{a}-\mathrm{c}), 0.86(\mathrm{~d})$ and $0.54 \mathrm{nA}(\mathrm{e}), v=2.8(\mathrm{a}-\mathrm{c}), 2.0(\mathrm{~d})$ and $7.8 \mathrm{~Hz}(\mathrm{e})$, scale bars: 10 $(\mathrm{a}, \mathrm{d}), 5(\mathrm{~b})$ and $1 \mathrm{~nm}(\mathrm{c}, \mathrm{e})$.

observable at position $2 \mathrm{a}$ and $2 \mathrm{~b}$ as well as similar atomically flat regions without a moiré pattern $(2 \mathrm{c}$ and $2 \mathrm{~d})$. These regions show that graphene has started to grow from the edges of the facet, as observed before ${ }^{17}$. If graphene starts to grow during a post-annealing of one hour at $665^{\circ} \mathrm{C}$, it can be expected that graphene should show up on large parts of the NP's facets upon even longer annealing times. Indeed, after the last annealing step of the PdNPs at $675^{\circ} \mathrm{C}$ (Figure 1g), some graphene sheets appear on large parts of the NP's top 
facets, as shown in Figure 2d and e: graphene moiré patterns can be seen in, e.g., regions 1a, $1 \mathrm{~b}$ and $1 \mathrm{c}$ whereas the structureless sheets in regions $2 \mathrm{a}$ and $2 \mathrm{~b}$ are also sheets of graphene with presumably small moiré patterns where the STM resolution was not sufficiently strong enough to resolve the lattice of the patterns.

WF Reduction by Ethylene Cracking. We now compare the results of annealing NPs in UHV with experiments where as-prepared NPs are exposed to ethylene at $660^{\circ} \mathrm{C}$. Note that the exposure times used for the ethylene annealing experiments are much shorter ( $<15$ minutes) than the high-temperature annealing times from above $(\leqq 1$ hour). Therefore, all phenomena that are discussed in the following can be assigned entirely to a cracking of ethylene over the PdNPs, and not to a carbon etching of the HOPG support.

Figure 3a-d show four KPFM measurements obtained on one and the same sample surface. The measurement in Figure 3a is the same as the one in Figure 1c, directly obtained after the NP preparation at $480{ }^{\circ} \mathrm{C}$ in UHV and prior to experiments with ethylene. The as-prepared NPs exhibit a slightly higher WF than the atomically flat HOPG surface in the vicinity $(\triangle \phi=+0.4 \mathrm{eV})$. The second KPFM measurement in Figure 3b shows the NPs after an annealing at $650^{\circ} \mathrm{C}$ in 22 Langmuir $(\mathrm{L})$ of ethylene $\left(p_{\mathrm{C}_{2} \mathrm{H}_{4}}=1 \times 10^{-6} \mathrm{mbar}\right)$. A recent STM study has shown that after such a short ethylene exposure, a carbon precursor structure is formed ${ }^{17}$ like the one from Figure 2 a to c. Such structures do not change the NP's WF to any large degree $(+0.4 \mathrm{eV}$ in Figure $3 \mathrm{~b})$.

However, the WF decreases when the NPs are annealed during longer ethylene exposure: the KPFM measurement in Figure 3c shows the same sample after a total ethylene exposure of $247 \mathrm{~L}$. In this case, the WF of the NPs is much smaller and has reached a WF value that is below the one of HOPG $(\triangle \phi \approx-0.10 \pm 0.03 \mathrm{eV})$ leading to a dark NP contrast in the WF image. Following experiments with a total ethylene exposure of $585 \mathrm{~L}$ (Figure 3d) and $2835 \mathrm{~L}$ (not shown) exemplify that the WF difference between the PdNPs and the HOPG surface remains unchanged. With respect to morphological and structural changes of the top (111) facets of the PdNPs, it is known that single layer graphene is formed after a few 

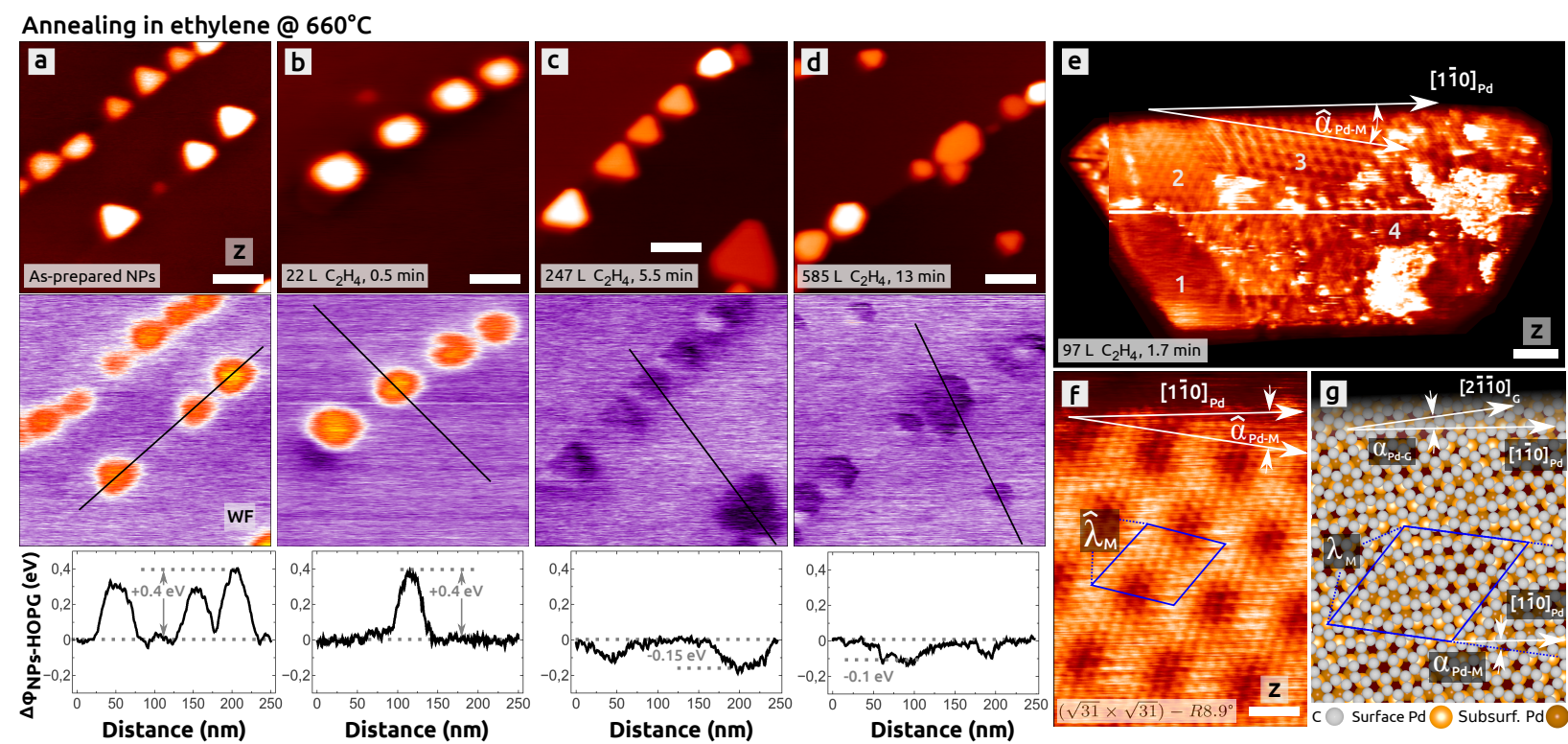

Figure 3: (a-f): The WF dependence of HOPG supported PdNPs on the post-annealing in ethylene at $660^{\circ} \mathrm{C}$. Total $\mathrm{C}_{2} \mathrm{H}_{4}$ exposures: $0 \mathrm{~L}$ (a), $22 \mathrm{~L}$ (b), $247 \mathrm{~L}$ (c) and $585 \mathrm{~L}$ (d). One KPFM experiment is represented by a pair of two vertically arranged images with a representative WF profile underneath. The images on the top represent the topography and the images below show the WF $(\triangle f=-6.7$ (a), -7.4 (b), -10.7 (b), $-7.9 \mathrm{~Hz}$, all: $v=0.5 \mathrm{~Hz})$. (e) STM topography image of a G@PdNP after an ethylene dosage of $97 \mathrm{~L}$ at $665^{\circ} \mathrm{C}\left(U_{\text {Bias }}=-\right.$ $0.25 \mathrm{~V}, I=1.94 \mathrm{nA}, v=3.0 \mathrm{~Hz})$, showing the previously observed $(\sqrt{3} \times \sqrt{3})-\mathrm{R} 30.0^{\circ}(1)$ and $(5 \times 5)$ - R0. $0^{\circ}$ moiré pattern $(2)^{17}$ together with the new $(\sqrt{31} \times \sqrt{31})$ - R8.9 moiré pattern (3) from Figure 2. For more details see Figure S3 in the Supporting Information. (f) STM topography image of the latter moiré pattern $\left(U_{\text {Bias }}=0.091 \mathrm{~V}, I=1.12 \mathrm{nA}, v=5.0 \mathrm{~Hz}\right)$ with the corresponding ball model (g). NP dimension (mean values): $h_{\mathrm{NP}}=7$ (a), 13 (b), 8 (c) and $8 \mathrm{~nm}, r_{\mathrm{NP}}=15$ (a), 23 (b), 22 (c) and $16 \mathrm{~nm}$ (d), scale bars: 50 (a-d), 5 (e) and $1 \mathrm{~nm}(\mathrm{f})$.

hundred Langmuir of ethylene at $650{ }^{\circ} \mathrm{C}^{17}$. As illustrated in Figure 3e-g, graphene already covers relatively large parts of the NP after a total ethylene exposure of $97 \mathrm{~L}$ whereas after higher dosages of a few hundreds of Langmuir, graphene covers the entire top (111) facet as exemplified in Figure 4. The quality of the graphene is better than in the case where the HOPG support is used as a carbon source.

Overall we can conclude that the WF difference between the PdNPs and HOPG is negative $(-0.10 \pm 0.03 \mathrm{eV})$ when graphene is covering the Pd's (111) facets. If we consider our experimental WF value of the HOPG surface $\left(\phi_{\mathrm{HOPG}}=4.3 \pm 0.1 \mathrm{eV}\right)$, the graphene encapsulated PdNPs have a WF of $\phi_{\mathrm{G} @ \mathrm{Pd}}=4.2 \pm 0.1 \mathrm{eV}$, which means that the WF of graphene on 


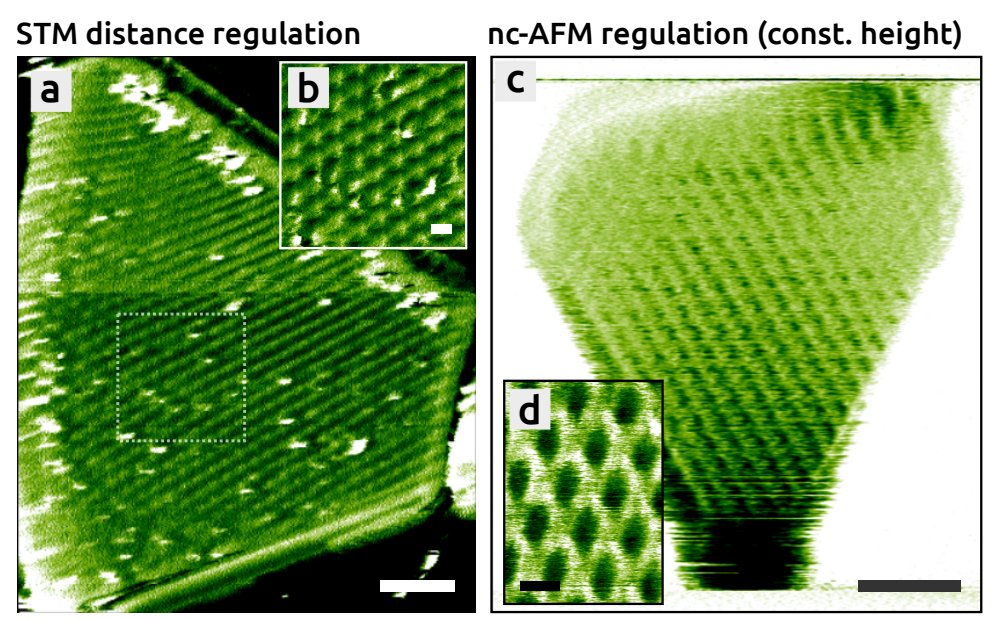

Figure 4: STM (a,b) and nc-AFM (c,d) regulated measurements obtained on G@PdNPs after a growth of graphene at $665{ }^{\circ} \mathrm{C}$ in $2835 \mathrm{~L}$ of $\mathrm{C}_{2} \mathrm{H}_{4}$. All images show the detuning $(\triangle f)$ signal. A bright image contrast corresponds to more positive detuning values and vice-versa. Images $(\mathrm{a}, \mathrm{b})$ are constant tunnel current and $(\mathrm{c}, \mathrm{d})$ constant height mode images. The two moiré patterns on both NPs are a $2.25 \mathrm{~nm}$ large $(\sqrt{67} \times \sqrt{67})-\mathrm{R} 12.2^{\circ}$ (a,b) and $2.47 \mathrm{~nm}$ large $(9 \times 9)-\mathrm{R} 0.0^{\circ}$ moiré pattern $(\mathrm{c}, \mathrm{d})$. More details can be found in Figure S4 of the Supporting Information. STM parameters: $U_{\text {Bias }}=-1.60$ (a) and $-0.50 \mathrm{~V}$ (b), $I=0.24$ (a) and $0.050 \mathrm{nA}(\mathrm{b}), v=1.3 \mathrm{~Hz}$ (both), nc-AFM parameters: averaged $\triangle f=-6.0$ (c) and $-58.5 \mathrm{~Hz}(\mathrm{~d}), U_{\text {Bias }}=0.50(\mathrm{c})$ and $0.020 \mathrm{~V}(\mathrm{~b}), v=9.8 \mathrm{~Hz}$ (both), scale bars: 10 (a,c) and $2 \mathrm{~nm}$ $(\mathrm{b}, \mathrm{d})$.

the PdNPs is smaller by $\triangle \phi_{\mathrm{Pd}-\mathrm{G} @ \mathrm{Pd}}=-1.4 \pm 0.1 \mathrm{eV}$ with respect to clean $\mathrm{Pd}(111)\left(\phi_{\mathrm{Pd}, \mathrm{lit}}=\right.$ $5.6 \pm 0.1 \mathrm{eV})$. This result is in agreement with experimental results obtained on $\operatorname{Pd}(111)$ single crystal surfaces $\left(\triangle \phi_{\mathrm{Pd}-\mathrm{G} @ \mathrm{Pd}}=-1.3 \mathrm{eV}^{51},-1.0 \mathrm{eV}^{35}\right.$ and $\left.-1.0 \mathrm{eV}^{52}\right)$ as well as with theoretical values $\left(-1.45 \mathrm{eV}^{51},-1.2 \mathrm{eV}^{35}\right.$ and $\left.-1.64 \mathrm{eV}^{53,54}\right)$.

Density Functional Theory Calculations. The results from the previous Section are summarized in Table 1. To elucidate the origin of the observed changes in the WF, we use DFT-calculations and explore a range of representative configurations of carbon on and in $\operatorname{Pd}(111)$. All DFT results are summarized in Table 2.

Palladium is an fcc metal with an experimental lattice constant of $a_{\mathrm{Pd}, \mathrm{lit}}=3.89 \pm 0.01 \AA$ (see Supporting Information). We calculate the lattice constant to be 3.98 or $3.87 \AA$ using GGA and LDA, respectively. The overestimation by GGA and slight underestimation by LDA is consistent with previous reports ${ }^{55}$. For the WF for the pristine $\operatorname{Pd}(111)$ surface, 
Table 1: Experimental and literature values for the WF of HOPG, Pd(111) and $\mathrm{PdNPs}$ (in $\mathrm{eV}$ ). If applicable, the $\mathrm{WF}$ difference with respect to clean $\mathrm{Pd}(111)$ $\left(\triangle \mathrm{WF}=\phi_{\mathbf{P d}}-\mathrm{WF}\right)$ is listed (in $\left.\mathrm{eV}\right)$. Furthermore, a few important comments are mentioned.

\begin{tabular}{lrrl}
\hline & WF & $\triangle W F$ & Comment \\
\hline HOPG, exp., this work & $4.3 \pm 0.1$ & $/$ & calibrated with $\operatorname{Ag}(001)$ \\
HOPG, literature & $4.5 \pm 0.1$ & $/$ & see Tab. S3 \\
Pd(111), literature & $5.6 \pm 0.1$ & $/$ & see Tab. S4 \\
Pd island growth @ RT & $5.7 \pm 0.1$ & clean Pd(111) \\
PdNP growth @ $150{ }^{\circ} \mathrm{C}$ & $5.2 \pm 0.1$ & $-0.5 \pm 0.1$ & mobile NPs, C inside \\
PdNP growth @ $480^{\circ} \mathrm{C}$ & $4.7 \pm 0.1$ & $-0.9 \pm 0.1$ & mobile NPs, C inside \\
PdNP + C precursor & $\sim 4.7$ & $\sim-1$ & fixed NPs \\
PdNP + graphene & $4.2 \pm 0.1$ & $-1.4 \pm 0.1$ & fixed NPs \\
\hline
\end{tabular}

we obtain $5.24 \mathrm{eV}$ (GGA) and $5.70 \mathrm{eV}$ (LDA). These values are consistent with previous computational reports (see Table S4 in the Supporting Information). With respect to the literature value, we find that $\mathrm{LDA}$ is closer to the experimental value of $\phi_{\mathrm{Pd}, \mathrm{lit}}=5.6 \pm 0.1 \mathrm{eV}$ (see Table S4 in the Supporting Information) than the GGA. Because of this, we will in the following concentrate on the LDA values for the WF.

Carbon is adsorbed on $\operatorname{Pd}(111)$ in a three-fold hollow position (Figure 5b). The fcc and hcp sites are quasi isoenergetic ${ }^{11}$ and here we report only the fcc values. The presence of carbon atoms on the surface yields an increased WF as a consequence of a charge transfer from the metal to carbon, which creates a dipole pointing into the surface (Figure 5c). The WF increase with respect to the pristine surface is $\Delta \phi=+0.35 \mathrm{eV}$ for $0.25 \mathrm{ML}$ of carbon, which increases to $+0.56 \mathrm{eV}$ for a $0.5 \mathrm{ML}$ coverage (Figure $6 \mathrm{~b}$ and $\mathrm{c}$ ) - a trend being in agreement with previous DFT results ${ }^{28,35}$. This shows that the phenomena of WF reduction observed experimentally cannot be explained by a low concentration of carbon $(<0.5 \mathrm{ML})$ adsorbed on the NPs. In the following, the case with $0.25 \mathrm{ML}$ of carbon is taken as a reference for the relative stability of all following considered structures.

Diffusion of atomic carbon into subsurface sites is energetically preferred in agreement 
Table 2: DFT values for the relative energy $\triangle E_{\text {tot }}$ (in $\mathrm{eV}$ ) and $\mathrm{WF}$ values (in $\mathrm{eV}$ ) in dependence on GGA and LDA for different $\operatorname{Pd}(111) / C$ configurations and graphene on $\operatorname{Pd}(111)$. The stability is calculated with respect to carbon adsorbed on $\mathrm{Pd}(111)$ at $0.25 \mathrm{ML}$ coverage using $\mathrm{Pd}$ bulk as a metal reservior $\left(\triangle E_{\text {tot }}\right)$. The labels SV, SA, SL, and SSL denote surface Pd vacancy, ad-atom, carbon on the first surface layer and carbon in a subsurface layer, respectively. 25,50 and $100 \%$ correspond to $0.25,0.5$ and $1.0 \mathrm{ML}$ coverage, respectively.

\begin{tabular}{|c|c|c|c|c|}
\hline & $\triangle E_{\mathrm{tot}}$ & $\mathrm{WF}$ & WF & $\triangle W F$ \\
\hline Configuration & GGA & GGA & LDA & LDA \\
\hline$\overline{\mathrm{Pd}(111)}$ & - & 5.24 & 5.70 & 0 \\
\hline $\mathrm{Pd}(111)+\mathrm{SD}(25 \%)$ & 0.82 & 4.83 & 5.28 & -0.42 \\
\hline $\operatorname{Pd}(111)+\mathrm{SA}(25 \%)$ & & & 4.30 & -1.40 \\
\hline $25 \% \mathrm{SL}$ & 0 & 5.68 & 6.05 & 0.35 \\
\hline $50 \% \mathrm{SL}$ & 0.66 & 5.97 & 6.26 & 0.56 \\
\hline $25 \% 1^{\text {st }} \mathrm{SSL}$ & -0.57 & 5.15 & 5.61 & -0.09 \\
\hline $50 \% 1^{\text {st }} \mathrm{SSL}$ & -0.14 & 5.05 & 5.50 & -0.21 \\
\hline $100 \% 1^{\text {st }} \mathrm{SSL}$ & 0.87 & 4.90 & 5.27 & -0.44 \\
\hline $25 \% \mathrm{SL}+25 \% 1^{\text {st }} \mathrm{SSL}$ & -0.08 & 5.67 & 6.04 & 0.34 \\
\hline $25 \% 1^{\text {st }} \mathrm{SSL}+25 \% 2^{\text {nd }} \mathrm{SSL}$ & -0.42 & 5.13 & 5.59 & -0.11 \\
\hline Deep SSL & -0.40 & 5.24 & 5.71 & 0.00 \\
\hline $\mathrm{Pd}_{6} \mathrm{C}$ & -0.71 & 5.04 & 5.55 & -0.15 \\
\hline$\sqrt{3} \times \sqrt{3}($ at $3.0 \AA)$ & -1.40 & 4.81 & 4.67 & -1.03 \\
\hline$\sqrt{3} \times \sqrt{3}\left(\right.$ at $\left.2.4 \AA^{17}\right)$ & & & 4.30 & -1.40 \\
\hline$\sqrt{3} \times \sqrt{3}+\mathrm{Pd}_{6} \mathrm{C}$ & -1.21 & 4.88 & 4.68 & -1.02 \\
\hline$\sqrt{3} \times \sqrt{3}+\mathrm{SD}$ & -0.50 & 4.63 & 4.35 & -1.35 \\
\hline $25 \% 1^{\text {st }} \mathrm{SSL}+25 \% \mathrm{SD}$ & 0.19 & 4.69 & 5.14 & -0.56 \\
\hline $50 \% 1^{\text {st }} \mathrm{SSL}+25 \% \mathrm{SD}$ & 0.58 & 4.57 & 5.02 & -0.69 \\
\hline $100 \% 1^{\text {st }} \mathrm{SSL}+25 \% \mathrm{SD}$ & 1.41 & 4.55 & 4.91 & -0.80 \\
\hline
\end{tabular}




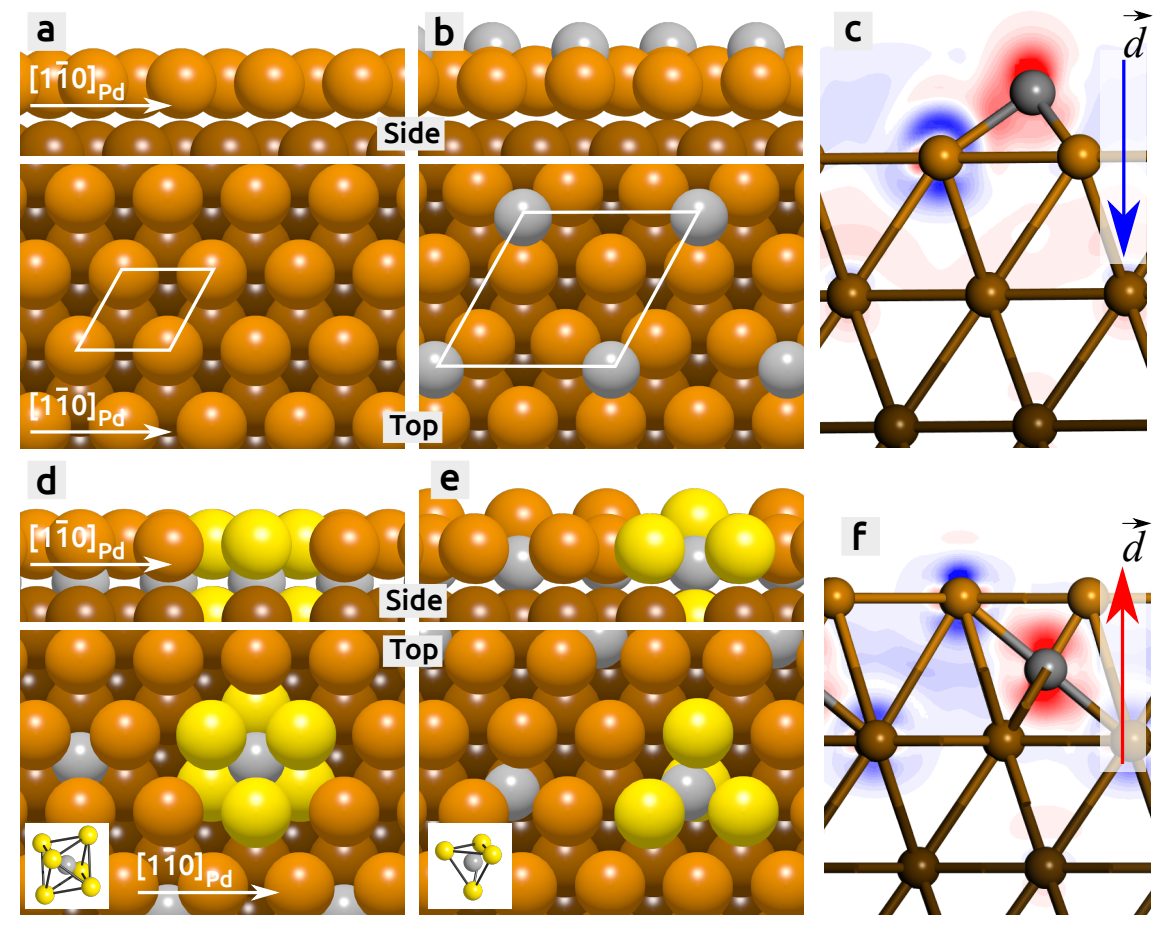

Figure 5: Different configurations for carbon on and in $\operatorname{Pd}(111)$. (a) The clean $\operatorname{Pd}(111)$ surface with the surface cell (white rhombus) shown in side and top views. (b) $0.25 \mathrm{ML}$ carbon in a fcc adsorption site forming a $\mathrm{p}(2 \times 2)$ superstructure (white rhombus). (c) Owing to the charge transfer from the metal to carbon (red: gain, blue: depletion of electrons), a surface dipole is created pointing into the surface, which leads to a WF reduction. (d,e) $0.25 \mathrm{ML}$ carbon in the $1^{\text {st }}$ subsurface layer at an octahedral $(\mathrm{d})$ and tetrahedral interstitial site (e). (f) The surface dipole is in this case opposite to the one in (c) owing to a charge transfer to carbon in the subsurface region.

with previous DFT reports ${ }^{11,27,28}$ : when carbon is adsorbed in the first subsurface layer in an octahedral (Figure 5d) or tetrahedral interstitial site (Figure 5e), we calculate the energy gain to be -0.57 and $-0.06 \mathrm{eV}$, respectively. In agreement with previous work ${ }^{27,28}$, the octahedral site is preferred by about $-0.5 \mathrm{eV}$. The barrier for diffusion from the surface to the octahedral site is $0.47 \mathrm{eV}$ (obtained using a $\mathrm{p}(3 \times 3)$ surface cell). The presence of subsurface carbon and a charge transfer from the metal to the carbon creates a dipole in opposite direction as compared to carbon adsorbed on the surface. This leads to a WF decrease of $-0.1 \mathrm{eV}$ for a 0.25 ML coverage, which is in agreement with previous DFT work ${ }^{28,35}$. The WF reduction does not change much when applying a strain of $\pm 1 \%$ on the $\operatorname{Pd}(111)$ lattice $^{13}$ : when the lattice is contracted, the WF increases by only $+0.03 \mathrm{eV}$, whereas it decreases by $-0.03 \mathrm{eV}$ 


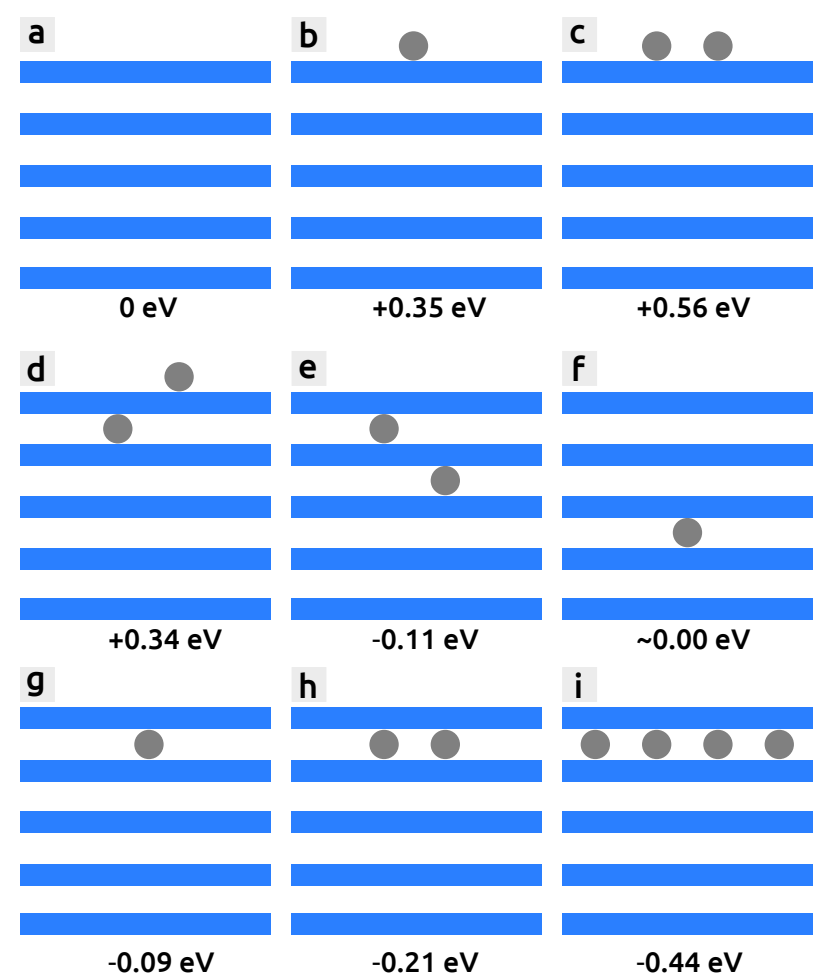

Figure 6: Amount of carbon on and/or in the surface (side view). A blue bar corresponds to one atomic palladium layer. Each gray dot equals $0.25 \mathrm{ML}$ of carbon.

when it is expanded.

Interestingly, if we consider $0.25 \mathrm{ML}$ carbon on the surface and $0.25 \mathrm{ML}$ carbon in the first subsurface layer (Figure 6d), the WF-change remains on the value that is obtained for only $0.25 \mathrm{ML}$ surface carbon $(+0.34$ vs. $+0.35 \mathrm{eV})$. Thus, the dipole is determined by the top most carbon layer. The same behaviour is observed when $0.25 \mathrm{ML}$ carbon are placed on both the first and second subsurface layer (Figure 6e). In both cases, the shift with respect to the prestine surface is about $-0.1 \mathrm{eV}$. Carbon should be close to the surface in order to give a WF change: in the case of carbon deep into the surface (Figure 6f), the metallic screening renders the influence on the WF very small.

Presence of carbon in the first subsurface layer reduces strongly the WF and could therefore explain our experimental observations. Experimentally, we do not have any direct information on the carbon coverage and atomic distribution in the subsurface layer. Because of this, we consider a range of different coverages and distributions (Figure 6g-i and Figure S5 
in the Supporting Information). The presence of carbon in the first subsurface layer results in a reduced WF, and the reduction is enhanced by increasing the coverage: the largest reduction is obtained with a full carbon monolayer in the subsurface layer $(-0.44 \mathrm{eV})$, which is, however, still smaller than the highest WF reduction experimentally observed $(\sim-1 \mathrm{eV})$. Furthermore, such a high coverage is clearly endothermic $(\triangle E=+0.87 \mathrm{eV})$ with respect to carbon on the surface and, consequently, improbable.

It is known that palladium carbides may form when $\mathrm{Pd}$ is exposed to carbonaceous species $^{18}$. Even if this system is energetically unfavored with respect to the formation of graphene ${ }^{29}$ (see also below), it may form as an intermediate structure. For $\mathrm{Pd}_{6} \mathrm{C}(111)^{29}$ (Figure $7 \mathrm{a}$ and $\mathrm{b}$ ) we calculate the WF to be $\phi=5.55 \mathrm{eV}$, which leads to a reduction of only $-0.15 \mathrm{eV}$ with respect to pristine $\mathrm{Pd}(111)$, as also predicted by other DFT results ${ }^{35}$.

We now focus on graphene on $\operatorname{Pd}(111)$, where we consider one observed graphene configuration on $\operatorname{Pd}(111)^{17}$, namely the $(\sqrt{3} \times \sqrt{3})-\mathrm{R} 30.0^{\circ}$ structure (Figure $7 \mathrm{c}$ ). Apart from a clean $\operatorname{Pd}(111)$ support, we also consider a possible influence of a carbide, namely the $\mathrm{Pd}_{6} \mathrm{C}(111)$ surface that supports the $\sqrt{3} \times \sqrt{3}$ graphene structure (Figure 7d). All structures are energetically preferred (Table 2). The WF for a graphene covered $\mathrm{Pd}(111)$ is $4.55 \mathrm{eV}$ at the preferred graphene-metal distance $(\sim 3.0 \AA)$, which leads to a WF reduction of $\triangle \phi=-1.03 \mathrm{eV}$ with respect to clean $\mathrm{Pd}(111)$. It should be noted that the WF shift is very sensitive to the carbon-metal distance (Figure 7e) and the shift is calcluated to be about $-1.4 \mathrm{eV}$ when considering the experimental distance of $2.4 \AA^{17}$. Our values are in good agreement with our experimental value of $-1.4 \mathrm{eV}$ and values from previous theoretical work $\left((\sqrt{7} \times \sqrt{7})-\mathrm{R} 19.1^{\circ}\right.$ : $-1.45 \mathrm{eV}(\mathrm{LDA})^{51},(\sqrt{3} \times \sqrt{3})-\mathrm{R} 30.0^{\circ}$ like: $-1.2 \mathrm{eV}(\mathrm{LDA})^{35}$ and $(\sqrt{3} \times \sqrt{3})-\mathrm{R} 30.0^{\circ}:-1.64 \mathrm{eV}$ $(\mathrm{LSDA})^{53,54}$. With respect to the carbide, graphene adsorption on the carbide surface has minor effects on the WF. Furthermore, such a configuration is slightly less energetically favoured with respect to the graphene on the perfect $\operatorname{Pd}(111)$ surface (see Table 2), which does not exclude a priori carbon in the PdNP in the presence of graphene sheet. An interesting question concerns the physical explanation of the WF reduction: it is assumed that 


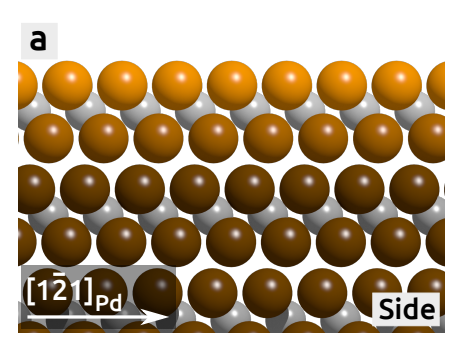

c
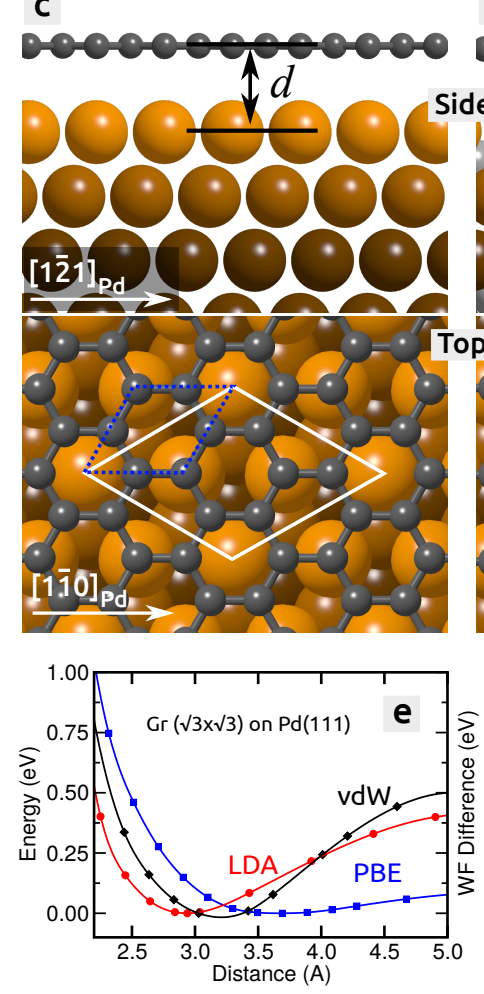

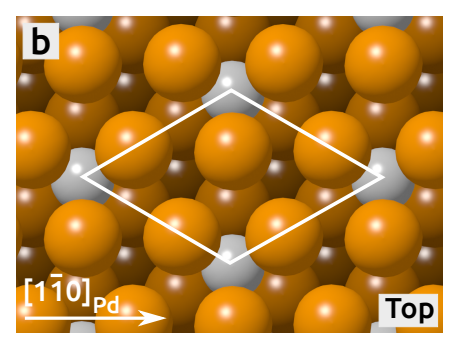

d
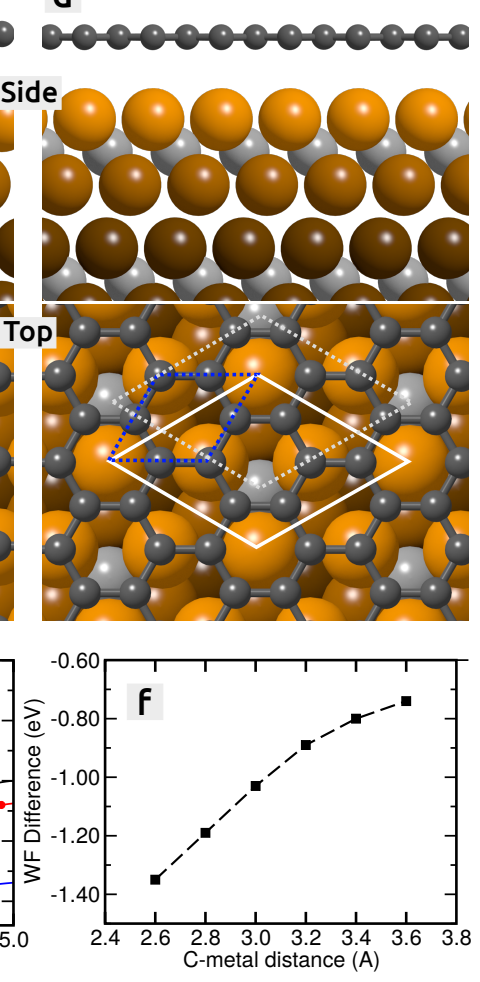

Figure 7: (a,b) The structure of $\mathrm{Pd}_{6} \mathrm{C}$ in a side (a) and top view (b). The $\sqrt{3} \times \sqrt{3}$ surface cell is indicated by a white rhombus. The carbide is composed of stacked octahedra with carbon in the center (a). The lattice constant of $\mathrm{Pd}_{6} \mathrm{C}$ is expanded by $\sim 3 \%$ with respect to pure $\mathrm{Pd}$ for both LDA and PBE. (c,d) graphene $\sqrt{3} \times \sqrt{3}$ (white rhombus) on $\operatorname{Pd}(111)$ (c) and $\mathrm{Pd}_{6} \mathrm{C}(111)(\mathrm{d})$. The blue and white rhombi show the surface cell of $\mathrm{Pd}(111)$ and the carbide, respectively. For both configurations, we choose the in-plane lattice constant of $\operatorname{Pd}(111)$ equal to its optimized value $\left(a_{\operatorname{Pd}(111)}=3.87 \AA\right.$, from LDA), adapting the lattice constant of the graphene accordingly. (e) The metal-graphene distance is $3.86 \AA$ in $\mathrm{PBE}$ and $3.00 \AA$ in LDA for the $\sqrt{3} \times \sqrt{3}$ structure on $\operatorname{Pd}(111)$. PBE is not expected to provide a proper structure for adsorbed graphene because of the absence of the van der Waals interactions. LDA, on the other hand provides a more reasonable metal-graphene distance. (f) The WF is strongly dependent on the graphene-metal bond distance, which explains the lower WF shift calculated in PBE. 
the WF of the graphene-covered $\operatorname{Pd}(111)$ is mainly influenced by the electronic properties of the graphene layer alone ${ }^{52}$. However, an analysis of the density of states (Figure S6 in the Supporting Information) shows that rather the Pd(111) determines the WF, under the influence of the graphene. Because there is no net charge transfer between $\operatorname{Pd}(111)$ and graphene, the WF change is owing to an electrostatic compression as explained for dielectric ultra-thin films on metal surfaces ${ }^{56}$. This effect is demonstrated in Figure $7 f$, where the WF strongly changes with the graphene-metal bond distance.

So far, theory qualitatively agrees with experiments, predicting a WF reduction when carbon is absorbed in the first subsurface layer, and quantitatively agrees with the experimental strong WF reduction, when graphene is supported on $\mathrm{Pd}(111)$. To match the experimental values for subsurface carbon on a quantitative level, a possibility to reduce the WF further is the formation of metal defects, i.e., palladium vacancies. The motivation comes from the fact that the presence of steps are experimentally known to reduce the $\mathrm{WF}^{57}$. We illustrate the effect of defects by considering point defects, i.e., metal surface vacancies in the first surface layer of $\operatorname{Pd}(111)$. Because we do not know the real structure of possible palladium defects, we consider for simplicity a $2 \times 2$ vacancy superstructure $(0.25 \mathrm{ML}$ ) (Figure S5 in the Supporting Information).

A reduction of already $-0.42 \mathrm{eV}$ is observed for only the palladium vacancies (see Table $2)$. If carbon is additionally put into the same subsurface positions from above $(0.25,0.5$ and 1.0 ML, Figure S5 in the Supporting Information) the WF decreases by $-0.8 \mathrm{eV}$ (see Table 2). If graphene is supported on a 0.25 ML defective $\mathrm{Pd}(111)$ surface (see Figure $\mathrm{S} 7$ in the Supporting Information), the WF reduction of $-1.35 \mathrm{eV}$ is calculated which is larger than the $-1.03 \mathrm{eV}$ shift on the prestine $\mathrm{Pd}(111)$ surface. Thus, one possibility for the large $\mathrm{WF}$ reductions we observed at all NPs is partially due to the presence of additional Pd defects. 


\section{DISCUSSION}

It is well known that NPs made from metal with a high carbon solubility ${ }^{20}$ can etch the steps and edges of HOPG and graphene, as shown with NiNPs ${ }^{58}$, FeNPs $^{59}$ and $\operatorname{CoNPs}^{60}$. The etching appears at mostly high temperatures $\left(750\right.$ to $1100{ }^{\circ} \mathrm{C}$ for NiNPs, $900{ }^{\circ} \mathrm{C}$ for FeNPs and $600{ }^{\circ} \mathrm{C}$ for CoNPs) under a catalytic hydrogenation of graphite ${ }^{58-60}$. Whereas the experimental observation is solid, the interpretation of the hydrogenation process itself is still under debate: either the metal NP detaches carbon atoms from the HOPG edges such that the carbon atoms diffuse into the NP and react with hydrogen on the NP's facets ${ }^{58,59}$. Or molecular hydrogen dissociatively adsorbs on the NP and diffuses into the NP, where it reacts with carbon at the edges ${ }^{60}$.

In our case, we have clear experimental signatures that it is the PdNPs, which catalyzes the etching of carbon from the HOPG steps: (a) in none of our experiments, hydrogen is explicitly dosed during the NP growth or the post-annealing. Even though the pressure of the residual gas is at $3 \times 10^{-9}$ mbar during the NP growth, with hydrogen as the main source, a hydrogen dosage of $\sim 0.4 \mathrm{~L}(3 \mathrm{~min})$ rules out the importance of hydrogen in our experiments. Furthermore, during long post-annealing experiments in $\mathrm{UHV}$ at $650{ }^{\circ} \mathrm{C}$ $\left(\mathrm{p}_{\mathrm{UHV}}=7 \times 10^{-10} \mathrm{mbar}\right.$ in average) graphene is formed on the NP's facets after a few hours. A hydrogen dosage of $\sim 3 \mathrm{~L}(1.5$ hours $)$ is too small to detach the large number of carbon atoms from HOPG needed to form graphene sheets on the NPs. (b) Hydrogen would not allow a growth of graphene on the top facets of the $\mathrm{NPs}^{60}$, it would instead produce hydrocarbons. With this, we can conclusively explain the carbon absorption during the NP growth: at the very beginning of the NP growth, the first palladium atoms nucleate at the HOPG steps forming dimers, trimers and very small NPs containing a few atoms only. The melting temperature of such palladium species is considerably lower in comparison to bulk palladium $\left(275^{\circ} \mathrm{C}\right.$ and $640{ }^{\circ} \mathrm{C}$ for a 0.5 and $1 \mathrm{~nm}$ small $\mathrm{NP}$, respectively, in comparison to $1555^{\circ} \mathrm{C}$ for bulk $\mathrm{Pd}^{61}$ ), and furthermore they have many low-coordinated atom sites compared to their volume. This explains the high activity of such species with respect to the carbon etching at 
HOPG steps ${ }^{62}$ and also with respect to the relatively small growth temperature between 150 and $480^{\circ} \mathrm{C}$. The number of detached carbon should increase with the temperature, which is what we observe by the strong WF reduction (Figure 1d).

An import aspect is the conclusion that starting from a critical NP size that is reached during the growth, the etching process is insufficient because of the small number of lowcoordinated palladium atoms in the NP and the higher melting temperature: large NPs, as they are considered in this work, should not absorb carbon during a post-annealing at $480^{\circ} \mathrm{C}$, and this is what we do indeed observe (no further WF change for the NPs in Figure 1e). We therefore believe that during the growth, only a small amount of carbon is effectively absorbed in the PdNPs, which agrees with the observation that after the growth no carbon structures are observed on the NPs. However, if in long post-annealing experiments the temperature is increased to $650^{\circ} \mathrm{C}$, a carbon precursor structure is formed, which subsequently is replaced by graphene upon extended annealing times (Figure 2). Obviously, the thermal energy is sufficiently high at $650^{\circ} \mathrm{C}$ to allow for a strong etching of a large amount of carbon, which is needed to form graphene.

Important to know is the atomic structure and composition of the (111) facets for a small amount of absorbed carbon. Our DFT calculations show that carbon atoms preferentially occupy the first subsurface region on the (111) facets. On $\operatorname{Pd}(111)$, diffusion of carbon towards the bulk is not preferred, in agreement with other work ${ }^{27,28,30}$. Subsurface carbon decreases the WF on the (111) facets, which is in qualitative agreement with our experimental observations (see Table 1 and 2). The DFT results are in quantitative agreement with the experiments when considering additional palladium defects like vacancies in the first atomic layer (Table 2). Whatever atomic structure the (111) facets adopts, the idea of introducing palladium defects is reasonable given the structural changes upon carbon absorption. In fact, the Pd vacancy formation energy is reduced with increasing carbon content in the first subsurface layer: the palladium vacancy formation energy decreases from $0.82 \mathrm{eV}$ for pristine $\mathrm{Pd}(111)$ to $0.76,0.72$ and $0.54 \mathrm{eV}$ for $0.25,0.5$ and $1.0 \mathrm{ML}$ of subsurface carbon, 
respectively. We expect that during the NP's growth, the thermal energy is sufficiently high to create such defects or similar ones. Indeed, some work suggests carbon-induced metal surface modifications where, e.g., carbon extracts single metal atoms from the surface ${ }^{31}$ or leads to modifications of the metal steps ${ }^{63}$. A recent work on $\mathrm{Co}(0001)$, clearly demonstartes the strong influence of carbon on the first cobalt layer, where the atoms reconstruct and some atoms get onto the surface by creating vacancy like defects ${ }^{32}$. Note that palladium ad-atoms on the $\mathrm{Pd}(111)$ strongly decrease the local WF, e. g., $0.25 \mathrm{ML}$ ad-atoms on the surface (Figure S5i in the Supporting Information) decrease the WF by $-1.4 \mathrm{eV}$ (see Table 2).

\section{SUMMARY AND CONCLUSIONS}

Our SPM and DFT work sheds light on carbon phenomena at (111) faceted PdNPs. Using UHV grown PdNPs on HOPG, we find that a small amount of carbon is etched from HOPG steps and dissolved in the metal during the growth of PdNPs at moderate temperatures (between 150 and $480^{\circ} \mathrm{C}$ ). The KPFM experiments show that the WF of as-prepared NPs decreases with an expected dependence on the growth temperature, whereas at $480^{\circ} \mathrm{C}$, a strong WF reduction of already $\sim-1 \mathrm{eV}$ is observed with respect to the WF of pristine $\mathrm{Pd}(111)$ $\left(\phi_{\mathrm{Pd}(111)}=5.6 \mathrm{eV}\right)$. DFT calculations show that the dissolved carbon atoms are located in the first subsurface layer on the (111) facet, being partially responsible for the WF reduction. We expect that additional palladium defects like vacancies in and ad-atoms on the first atomic layer assist the WF decrease of the NPs.

If as-prepared NPs are post-annealed for one hour in UHV at the much higher temperature of $650^{\circ} \mathrm{C}$, a large amount of carbon is etched from the HOPG steps by the NPs. As observed by STM, this results into the formation of a carbon precursor structure, which upon longer annealing times (1-2 hours) is replaced by graphene. Similar phenomena are observed when ethylene is cracked at $650{ }^{\circ} \mathrm{C}$ for a short time of minutes at as-prepared NPs whereas the graphene quality is mostly better. KPFM exhbits a very strong WF reduction of $-1.4 \mathrm{eV}$, 
which agrees with theory. With respect to the physical origin of the WF reduction, the DOS of the graphene $/ \mathrm{Pd}(111)$ system reveals an electrostatic compression effect. Thus, the WF of $\mathrm{Pd}(111)$ under the influence of graphene is measured, and not the WF of graphene alone.

Our work comprises some general observations and related perspectives: (a) in the presence of a small amount of subsurface and surface carbon, we suspect modifications of the first metal layer because the formation energy of palladium vacancies decreases considerably with increasing carbon content. We believe that this is a general phenomenon, which should be considered when dealing with carbon at NPs and on metal surfaces. In future, theory has to clarify the kinetical process on $\mathrm{Pd}(111)$ and other surfaces in a way as shown in Ref. 32 . (b) Care needs to be taken when growing PdNPs on carbon supports already at moderate temperatures: carbon is etched from the support even under UHV conditions and is absorbed into the NPs. We speculate that this phenomena probably takes place when also growing

other NPs made from, e.g., cobalt and iron. (c) Carbon precursor structures and graphene on the NP's facets, as well as a small amount of subsurface carbon below the facets can be well characterized and detected at the single NP level by SPM, and in particular with KPFM, which detects such phenomena by a measure of the WF alone. We believe that KPFM is a suitable and complementary local scanning probe technique, which has a high potential for applications in heterogeneous catalysis.

\section{ASSOCIATED CONTENT}

Supporting Information. Details about the sample preparation, UHV techniques (STM, nc-AFM and KPFM), image analysis, density functional theory (DFT) calculations, choice of WF values from literature, and supporting experiments and calculations (PDF).

\section{AUTHOR INFORMATION}

\section{Corresponding Author}


E-mail: barth@cinam.univ-mrs.fr

\section{ORCID}

Henrik Grönbeck: 0000-0002-8709-2889

Clemens Barth: 0000-0003-4250-4533

\section{Author Contributions}

C. B. conducted the experimental work whereas H. G. performed the calculations. C. B. and H. G. wrote the manuscript.

\section{Funding Sources}

Agence Nationale de la Recherche (ANR-17-CE09-0045, project REACTIVITY). Swedish Research Council (2016-05234).

\section{Notes}

The authors declare no competing financial interests.

\section{ACKNOWLEDGMENT}

Support from the Agence Nationale de la Recherche (ANR) through project REACTIVITY (grant ANR-17-CE09-0045-01) is gratefully acknowledged. H. G. acknowledges financial support from the Swedish Research Council (2016-05234). The calculations have been performed at C3SE (Göteborg) through a SNIC grant. C. B. highly acknowledges P. Bindzi for maintainance work at the UHV chamber.

\section{References}

(1) Albers, P.; Pietsch, J.; Parker, S. F. Poisoning and Deactivation of Palladium Catalysts. J. Mol. Catal. A 2001, 173, 275-286.

(2) Argyle, M.; Bartholomew, C. Heterogeneous Catalyst Deactivation and Regeneration: A Review. Catalysts 2015, 5, 145-269. 
(3) Teschner, D.; Borsodi, J.; Wootsch, A.; Revay, Z.; Havecker, M.; Knop-Gericke, A.; Jackson, S. D.; Schlögl, R. The Roles of Subsurface Carbon and Hydrogen in PalladiumCatalyzed Alkyne Hydrogenation. Science 2008, 320, 86-89.

(4) Freund, H.-J. Model Studies in Heterogeneous Catalysis. Chem. Euro. J. 2010, 16, 9384-9397.

(5) De Smit, E.; Weckhuysen, B. M. The Renaissance of Iron-Based Fischer-Tropsch Synthesis: On the Multifaceted Catalyst Deactivation Behaviour. Chem. Soc. Rev. 2008, $37,2758$.

(6) Moisala, A.; Nasibulin, A. G.; Kauppinen, E. I. The Role of Metal Nanoparticles in the Catalytic Production of Single-Walled Carbon Nanotubes - A Review. J. Phys. Condens. Matter 2003, 15, S3011-S3035.

(7) Jourdain, V.; Bichara, Ch. Current Understanding of the Growth of Carbon Nanotubes in Catalytic Chemical Vapour Deposition. Carbon N. Y. 2013, 58, 2-39.

(8) Wu, J.; Helveg, S.; Ullmann, S.; Peng, Z.; Bell, A. T. Growth of Encapsulating Carbon on Supported Pt Nanoparticles Studied by in Situ TEM. J. Catal. 2016, 338, 295-304.

(9) Fu, Q.; Bao, X. Catalysis on a Metal Surface with a Graphitic Cover. Chin. J. Catal. 2015, 36, 517-519.

(10) Deng, D.; Novoselov, K. S.; Fu, Q.; Zheng, N.; Tian, Z.; Bao, X. Catalysis with Two-Dimensional Materials and Their Heterostructures. Nat. Nanotechnol. 2016, 11, $218-230$.

(11) Kozlov, S. M.; Yudanov, I. V.; Aleksandrov, H. A.; Rösch, N. Theoretical Study of Carbon Species on Pd(111): Competition Between Migration of C Atoms to the Subsurface Interlayer and Formation of $\mathrm{C}_{\mathrm{n}}$ Clusters on the Surface. Phys. Chem. Chem. Phys. 2009, 11, 10955. 
(12) Yudanov, I. V.; Neyman, K. M.; Rösch, N. Density Functional Study of Pd Nanoparticles with Subsurface Impurities of Light Element Atoms. Phys. Chem. Chem. Phys. 2004, 6, 116-123.

(13) Neyman, K. M.; Schauermann, S. Hydrogen Diffusion Into Palladium Nanoparticles: Pivotal Promotion by Carbon. Angew. Chem. Int. Ed. 2010, 49, 4743-4746.

(14) Yoshida, H.; Takeda, S.; Uchiyama, T.; Kohno, H.; Homma, Y. Atomic-Scale In-Situ Observation of Carbon Nanotube Growth From Solid State Iron Carbide Nanoparticles. Nano Lett. 2008, 8, 2082-2086.

(15) Jiang, W.-J.; Gu, L.; Li, L.; Zhang, Y.; Zhang, X.; Zhang, L.-J.; Wang, J.-Q.; Hu, J.S.; Wei, Z.; Wan, L.-J. Understanding the High Activity of Fe-N-C Electrocatalysts in Oxygen Reduction: $\mathrm{Fe} / \mathrm{Fe}_{3} \mathrm{C}$ Nanoparticles Boost the Activity of Fe-N $\mathrm{x} . J$. Am. Chem. Soc. 2016, 138, 3570-3578.

(16) Murata, Y.; Petrova, V.; Kappes, B. B.; Ebnonnasir, A.; Petrov, I.; Xie, Y.-H.; Ciobanu, C. V.; Kodambaka, S. Moiré Superstructures of Graphene on Faceted Nickel Islands. ACS Nano 2010, 4, 6509-6514.

(17) Barth, C. Carbon Precursor Structures and Graphene on Palladium Nanoparticles. J. Phys. Chem. C 2018, 122, 522-529.

(18) Balmes, O.; Resta, A.; Wermeille, D.; Felici, R.; Messing, M. E.; Deppert, K.; Liu, Z.; Grass, M. E.; Bluhm, H.; van Rijn, R. et al. Reversible formation of a $\mathrm{PdC}_{\mathrm{x}}$ phase in $\mathrm{Pd}$ nanoparticles upon $\mathrm{CO}$ and $\mathrm{O}$ phase in $\mathrm{Pd}$ nanoparticles upon $\mathrm{CO}$ and $\mathrm{O}_{2}$ exposure. Phys. Chem. Chem. Phys. 2012, 14, 4796.

(19) Malina, O.; Jakubec, P.; Kaslik, J.; Tucek, J.; Zboril, R. A Simple High-Yield Synthesis of High-Purity Hägg Carbide $\left(\mathrm{x}-\mathrm{Fe}_{5} \mathrm{C}_{2}\right)$ Nanoparticles with Extraordinary Electrochemical Properties. Nanoscale 2017, 14, 10440-10446. 
(20) Yokoyama, H.; Numakura, H.; Koiwa, M. The Solubility and Diffusion of Carbon in Palladium. Acta Materialia 1998, 46, 2823-2830.

(21) Rose, M. K.; Borg, A.; Mitsui, T.; Ogletree, D. F.; Salmeron, M. Subsurface Impurities in $\operatorname{Pd}(111)$ Studied by Scanning Tunneling Microscopy. J. Chem. Phys. 2001, 115, 10927-10934.

(22) Mannie, G. J. A.; Lammich, L.; Li, Y.-W.; Niemantsverdriet, J. W. H.; Lauritsen, J. V. Monolayer Iron Carbide Films on $\mathrm{Au}(111)$ as a Fischer-Tropsch Model Catalyst. ACS Catal. 2014, 4, 3255-3260.

(23) Böller, B.; Ehrensperger, M.; Wintterlin, J. In Situ Scanning Tunneling Microscopy of the Dissociation of CO on Co(0001). ACS Catal. 2015, 5, 6802-6806.

(24) Brandt, B.; Schalow, T.; Laurin, M.; Schauermann, S.; Libuda, J.; Freund, H.-J. Oxidation, Reduction, and Reactivity of Supported Pd Nanoparticles: Mechanism and Microkinetics. J. Phys. Chem. C 2007, 111, 938-949.

(25) Gabasch, H.; Hayek, K.; Klötzer, B.; Knop-Gericke, A.; Schlögl, R. Carbon Incorporation in $\mathrm{Pd}(111)$ by Adsorption and Dehydrogenation of Ethene. J. Phys. Chem. B 2006, 110, 4947-4952.

(26) Libuda, J.; Freund, H.-J. Molecular Beam Experiments on Model Catalysts. Surf. Sci. Rep. 2005, 57, 157-298.

(27) Gracia, L.; Calatayud, M.; Andrés, J.; Minot, C.; Salmeron, M. Migration of the Subsurface C Impurity in Pd(111). Phys. Rev. B 2005, 71, 033407.

(28) Nykänen, L.; Andersin, J.; Honkala, K. First-Principles Calculations of the Initial Incorporation of Carbon Into Flat and Stepped Pd Surfaces. Phys. Rev. B 2010, 81, 075417. 
(29) Seriani, N.; Mittendorfer, F.; Kresse, G. Carbon in Palladium Catalysts: A Metastable Carbide. J. Chem. Phys. 2010, 132, 024711.

(30) Vines, F.; Loschen, Ch.; Illas, F.; Neyman, K. M. Edge Sites as a Gate for Subsurface Carbon in Palladium Nanoparticles. J. Catal. 2009, 266, 59-63.

(31) Wu, P.; Zhang, W.; Li, Z.; Yang, J.; Hou, J. G. Communication: Coalescence of Carbon Atoms on $\mathrm{Cu}(111)$ Surface: Emergence of a Stable Bridging-Metal Structure Motif. J. Chem. Phys. 2010, 133, 071101.

(32) Zhang, X.-Q.; van Santen, R. A.; Hensen, E. J. M. Carbon-Induced Surface Transformations of Cobalt. ACS Catal. 2015, 5, 596-601.

(33) Conrad, H.; Ertl, G.; Latta, E. E. Adsorption of Hydrogen on Palladium Single Crystal Surfaces. Surf. Sci. 1974, 41, 435-446.

(34) Behm, R. J.; Christmann, K.; Ertl, G.; van Hove, M. A. Adsorption of CO on Pd(100). J. Chem. Phys. 1980, 73, 2984-2995.

(35) Mok, H. S.; Ebnonnasir, A.; Murata, Y.; Nie, S.; McCarty, K. F.; Ciobanu, C. V.; Kodambaka, S. Kinetics of Monolayer Graphene Growth by Segregation on $\operatorname{Pd}(111)$. Appl. Phys. Lett. 2014, 104, 101606.

(36) Barth, C.; Foster, A. S.; Henry, C. R.; Shluger, A. L. Recent Trends in Surface Characterization and Chemistry with High-Resolution Scanning Force Methods. Adv. Mater. 2011, 23, 477-501.

(37) Palacios-Lidon, E.; Henry, C. R.; Barth, C. Kelvin Probe Force Microscopy in Surface Chemistry: Reactivity of Pd Nanoparticles on Highly Oriented Pirolytic Graphite. ACS Catal. 2014, 4, 1838-1844.

(38) Panchal, V.; Pearce, R.; Yakimova, R.; Tzalenchuk, A.; Kazakova, O. Standardization of Surface Potential Measurements of Graphene Domains. Sci. Rep. 2013, 3, 2597. 
(39) Filleter, T.; Emtsev, K. V.; Seyller, Th.; Bennewitz, R. Local Work Function Measurements of Epitaxial Graphene. Appl. Phys. Lett. 2008, 93, 133117.

(40) Temmen, M.; Ochedowski, O.; Schleberger, M.; Reichling, M.; Bollmann, T. R. J. Hydration Layers Trapped Between Graphene and a Hydrophilic Substrate. New J. Phys. 2014, 16, 133117.

(41) Ulbricht, H.; Zacharia, R.; Cindir, N.; Hertel, T. Thermal Desorption of Gases and Solvents From Graphite and Carbon Nanotube Surfaces. Carbon 2006, 44, 2931-2942.

(42) Barth, C.; Claeys, C.; Henry, C. R. Surface Preparation of Hard Ionic Crystals by Ultrahigh Vacuum Cleavage. Rev. Sci. Instr. 2005, 76, 083907.

(43) Kitamura, S.; Suzuki, K.; Iwatsuki, M. High Resolution Imaging of Contact Potential Difference Using a Novel Ultrahigh Vacuum Non-Contact Atomic Force Microscope Technique. Appl. Surf. Sci. 1999, 140, 265-270.

(44) Delley, B. From molecules to Solids with the DMol ${ }^{3}$ Approach. J. Chem. Phys. 2000, 113, 7756-7764.

(45) Vosko, S. H.; Wilk, L.; Nusair, M. Accurate Spin-Dependent Electron Liquid Correlation Energies for Local Spin Density Calculations: a Critical Analysis. Can. J. Phys. 1980, 58, 1200 .

(46) Perdew, J.; Burke, K.; Ernzerhof, M. Generalized Gradient Approximation Made Simple. Phys. Rev. Lett. 1996, 77, 3865.

(47) Singh-Miller, N. E.; Marzari, N. Surface Energies, Work Functions, and Surface Relaxations of Low-Index Metallic Surfaces from First Principles. Phys. Rev. B. 2009, 80, 235407.

(48) Patra, A.; Bates, J. E.; Sun, J.; Perdew, J. P. Properties of Real Metallic Surfaces: 
Effects of Density Functional Semilocality and Van der Waals Nonlocality. Proc. Nat. Acad. Sci. 2017, 114, E9188.

(49) de Heer, W. A. The Physics of Simple Metal Clusters: Experimental Aspects and Simple Models. Rev. Mod. Phys. 1993, 65, 611-676.

(50) Yuan, Z.; Hanf, M. C.; Stephan, R.; Dulot, F.; Denys, E.; Florentin, A.; Harbich, W.; Wetzel, P. Growth of Palladium Nanoparticles on Nanostructured Highly Ordered Pyrolytic Graphite. Surf. Interface Anal. 2015, 47, 82-86.

(51) Murata, Y.; Starodub, E.; Kappes, B. B.; Ciobanu, C. V.; Bartelt, N. C.; McCarty, K. F.; Kodambaka, S. Orientation-Dependent Work Function of Graphene on Pd(111). Appl. Phys. Lett. 2010, 97, 143114.

(52) Oshima, C.; Nagashima, A. Ultra-Thin Epitaxial Films of Graphite and Hexagonal Boron Nitride on Solid Surfaces. J. Phys. Condens. Matter 1997, 9, 1-20.

(53) Giovannetti, G.; Khomyakov, P. A.; Brocks, G.; Karpan, V. M.; van den Brink, J.; Kelly, P. J. Doping Graphene with Metal Contacts. Phys. Rev. Lett. 2008, 101, 026803.

(54) Khomyakov, P. A.; Giovannetti, G.; Rusu, P. C.; Brocks, G.; van den Brink, J.; Kelly, P. J. First-Principles Study of the Interaction and Charge Transfer Between Graphene and Metals. Phys. Rev. B 2009, 79, 026803.

(55) M. Körling; J. Häglund Cohesive and Electronic Properties of Transition Metals: The Generalized Gradient Approximation. Phys. Rev. B 1992, 45, 13293.

(56) Prada, S.; Martinez, U.; Pacchioni, G. Work Function Changes Induced by Deposition of Ultrathin Dielectric Films on Metals: A Theoretical Analysis. Phys. Rev. B 2008, 78, $1-8$.

(57) K. Besocke; B. Krahl-Urban; H. Wagner Dipole Moments Associated with Edge Atoms - Comparative Study of Stepped Pt, Au and Au Surfaces. Surf. Sci. 1977, 68, 39. 
(58) Ci, L.; Xu, Z.; Wang, L.; Gao, W.; Ding, F.; Kelly, K. F.; Yakobson, B. I.; Ajayan, P. M. Controlled Nanocutting of Graphene. Nano Res. 2008, 1, 116-122.

(59) Datta, S. S.; Strachan, D. R.; Khamis, S. M.; Johnson, A. T. C. Crystallographic Etching of Few-Layer Graphene. Nano Lett. 2008, 8, 1912-1915.

(60) Schäffel, F.; Warner, J. H.; Bachmatiuk, A.; Rellinghaus, B.; Büchner, B.; Schultz, L.; Rümmeli, M. H. Shedding Light on the Crystallographic Etching of Multi-Layer Graphene at the Atomic Scale. Nano Res. 2009, 2, 695-705.

(61) Kateb, M.; Azadeh, M.; Marashi, P.; Ingvarsson, S. Size and Shape-Dependent Melting Mechanism of Pd Nanoparticles. Journal of Nanoparticle Research 2018, 20, 251.

(62) Datta, Sujit S Wetting and Energetics in Nanoparticle Etching of Graphene. J. Appl. Phys. 2010, 108, 024307.

(63) Kwon, S.-Y.; Ciobanu, C. V.; Petrova, V.; Shenoy, V. B.; Bareno, J.; Gambin, V.; Petrov, I.; Kodambaka, S. Growth of Semiconducting Graphene on Palladium. Nano Lett. 2009, 9, 3985-3990. 


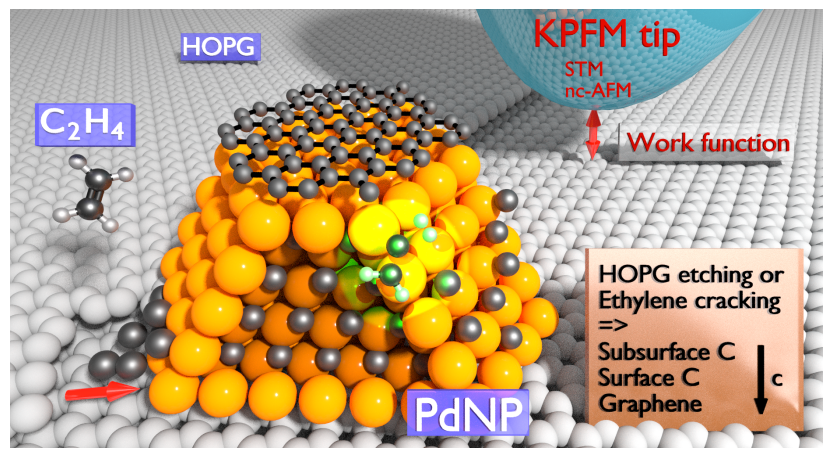

TOC IMAGE 